\title{
The Impact of Margin Trading on Stock Volatility: Based from 2014 to 2016 Shanghai and Shenzhen 300 Index
}

\author{
Chuanyang Gong ${ }^{1,2}$ \\ ${ }^{1}$ School of Management Shanghai University, China \\ ${ }^{2}$ College of Economics and Management Zhe Jiang A\&F University, China \\ Correspondence: Chuanyang Gong, School of Management Shanghai University, China. E-mail: \\ gcy17610@163.com
}

Received: March 8, 2021

Accepted: April 28, 2021

Online Published: May 25, 2021

doi:10.5539/ijbm.v16n6p32

URL: https://doi.org/10.5539/ijbm.v16n6p32

\begin{abstract}
The paper study the impact of margin trading on the volatility of the stock market, We selected 469 observation values among the daily Shanghai and Shenzhen 300 index from May 2014 to March 2016. the Granger causality test results are obtained for the model. Empirically study shows that one of the factors affecting stock price fluctuation does include margin trading business, and shows a negative correlation, which plays a more stable role in the stock market.
\end{abstract}

Key words: Margin trading, Stock market volatility, The Shanghai and Shenzhen 300 Index, Market stability

\section{Introduction}

For a long time, China's Security exchange market lacks reasonable Price Discovery mechanism. Stock prices often surge and drop as a result of investor 's reckless style. Therefore, the market systematic risk is higher. In order to improve this phenomenon, from 31 March 2010, our country has officially opened the margin trading system. This is a key step towards maturity in our country's stock market. Although compared with mature capital markets overseas, we do have a lot of restrictions and problems on margin trading. To solve these problems, we launched the margin lending business for the first time After proposing transfinancing business in February 2013. To some extent, this also marks the margin trading mechanism is gradually to normal.

From 2010 to 2010 the six years, margin trading have performed to stable the basic function of securities market, the stock market liquidity enhancement, this paper USES the econometrics method, through from May 2014 to March 2014 margin balance during the period of the data, found that the influence of the volatility of Shanghai and Shenzhen 300 index is my main exploration target.

\section{Literature}

From a global perspective, we can find that the earliest implementation of margin financing and short selling business was in Amsterdam stock exchange of Netherlands in 1607. With the development and progress of The Times, modern margin financing and short selling business originated from the United States. Many overseas scholars have many years of market research on margin trading and short selling business, and these years of market experience have led them to have detailed discussions and in-depth research on many aspects. Since 2010 , in order to improve the environment of the securities market, stabilize the price better and ease the pressure of the capital market, China has started to carry out the margin and short selling business. Therefore, many scholars in China have conducted in-depth or shallow research and discussions on this. Of course, there will be differences if there are discussions, and the most popular opinions are as follows: one view holds that the stock market becomes more stable after the implementation of margin financing and short selling business, which has a good effect of controlling the stock market fluctuation, and does not cause speculative bubble, so that the stock price can reflect the specific value of the company to some extent; However, another view holds that the stock market has increased its ups and downs after the margin lending and short selling business, which reduces the stability of the stock market and thus increases the volatility, causing the stock to deviate from its real value. The third view is that margin lending and short selling business has no significant effect on the long-term volatility of the stock market. 


\subsection{Margin Trading Increases the Volatility of the Stock Market}

According to the theoretical model established by Allen and Gale (1991), when margin trading is completely restricted, the stock market will be in perfect competition and equilibrium. When fully permitted, the stock market will be in the state of incomplete competition (Liang, 2015). To this end, financial reform and allowing short selling would undermine economic stability. Bernardo mud Welch (2004) use the modeling research approach, research by investors during the financial crisis of the relationship between anxiety and crisis, found that investors in the stock market volatility, as long as concern, in order to ensure that their investment will be immediately selling behavior, this kind of behavior if spread there's collective panic, and restrictions of trading guarantee to prevent copycat incidents, can make the stock market to maintain stable state (Yu, 2012). Chang et al. (2007) selected stock data of Hong Kong from 1992 to 2003 for research. By testing the impact of restricted margin trading on the stock market, it was concluded that short selling made stock valuation too high and could not reflect real value, resulting in increased stock volatility and impact on economic stability (Yang \& Zhang, 2012). Ofer and Richardson (2003) extracted stock data of 400 American Internet companies between January 1998 and December 2000. According to the research, by relaxing the margin trading threshold, a large number of new investors took short selling, resulting in the decline of stock prices and the eventual bursting of stock bubbles, Ellen and Gale(1991) agreed with them. Henry and McKenzie (2006) used the daily data of the stock market of the Hong Kong special administrative region from 1992 to 2003 to carry out a study and concluded that allowing short selling is the increase of the stock market amplitude. Research of Shkilko et al. (2008) shows that the short selling mechanism can lead to sharp fluctuations in the trading price of the stock market (Peng, 2015).

\subsection{Margin Trading Contributes to Market Stability and Restrains Volatility}

Woolsey and Dickinson (1994) conducted a thorough research and discussion on the stock market, and found that margin trading did not cause the sharp shock of sharp rise and fall of stock prices. Speculators do not profit from excess profits, but are instead price discovery. Can produce scale effect, make need cost reduces, improve security market stability thereby. Charoenrook and Daouk (2005) collected stock market data of 111 countries (23 developed countries and 88 emerging countries) from December 1969 to December 2002, and conducted empirical tests by using panel regression analysis and time exploration. Discuss how the short-selling constraints float the market's overall earnings. Compared with countries where margin trading is banned, the country's overall stock market is less volatile and more stable. Hong and Stein (2003) established a puzzle agent model to conduct research, and the results showed that if margin trading was prohibited, it would eventually lead to the stock market crash, resulting in a sharp fall. Liao Shi guang and Yang Zhaojun (2005) explored the monthly data of the Taiwan stock market, and the results proved that margin trading reduced the volatility of the stock market and improved the stability of the stock market (Cai, 2010). Gong Hongxia (2010), a Chinese scholar, collected data of Hong Kong stock market and used GARCH structure to show that margin trading has a significant impact on stock price volatility, playing an active role in stabilizing the market (Gong, 2010). Eric c.c. hang and Yan Luo, Jinjuan Ren (2013) reviewed the stock market volatility affected by margin exchanges in Chinese market from different perspectives. It was found that margin trading did not increase the volatility of the stock market, but played a stabilizing effect to a certain extent (Chang, Luo, \& Ren, 2006).

\subsection{Margin Trading Has no Significant Impact on the Long-Term Volatility of the Stock Market}

Wab and Figlawski (1993), an overseas scholar, explored the stock market. There was no strong correlation between short selling and late stock price fluctuation, that is, there was no significant impact. Kraus and Rubin (2003) explored the impact of easing margin trading restrictions on stock price volatility. The results show that it is possible to increase or decrease, and there is no significant effect. After studying the stock market, wang min, Liao Shiguang and $\mathrm{Wu}$ Shukun (2008) showed that the financing business enhanced the liquidity of the stock market, while the short selling business did not significantly enhance the liquidity of the stock market, and they had no significant impact on the fluctuation of the stock market subject. Chan Dongyu, Zhao Pei and Wei Qiliu (2014) to extract the CSI 90 shares of the two cities index data analysis and calculation of the day, excess volatility and earnings volatility of average, the conclusion shows that margin in our country have not the stock market liquidity has obvious improvement, in order to make the margin trading has his proper role, perfect the financial system and a sound regulatory warning mechanism is necessary (Dong, Zhao, \& Liu, 2014). Today, the margin of price fluctuation on the stock market influence to hold this three kinds of basic point of view, it is difficult to get a consistent conclusion. Most of the studies are conducted by foreign scholars based on the data of foreign years' experience in margin financing and short selling. The research of China is mainly focused on the stock market data of Hong Kong and Taiwan. China's domestic stock market or lack of targeted research results. Of course, this is also because China's margin trading project is just starting, still in the pilot stage. This 
paper selects the data of the CSI 300 index for a period of time, and makes an empirical analysis of the relationship between margin trading and stock market fluctuations.

\section{Model Construction and Data Sources}

\subsection{Model Construction}

Engle and Granger put forward the famous Granger expression theorem in 1987: "if the variables X and Y are co-integrated, the short-term disequilibrium between them can always be expressed by an error correction model:

$$
\Delta Y_{t}=\operatorname{lagged}(\Delta Y, \Delta X)-1-\lambda \mu_{t-1}+\varepsilon \quad 0<\lambda<1_{t}
$$

Through research, economists have found a method that can be used to analyze between two variables. Analyze whether there is a causal relationship between them. He defines causality as "the variance of the best least squares prediction that depends on the use of all information at some point in the past." Assumptions have sequence based on time sequence, exists in the $\mathrm{X}, \mathrm{Y}$ the granger causality relationship between the two economic variables defined as: "if in both $\mathrm{X}$ and $\mathrm{Y}$ the two variables before and under the condition of information to predict the effect of the variable $\mathrm{Y}$ than in the past only by $\mathrm{Y}$ alone information to forecast effect is good, $\mathrm{Y}$ that the variable $\mathrm{X}$ to explain the variable $\mathrm{Y}$ future change is good, is to recognize the $\mathrm{X}$ variable is the granger reason of causing $\mathrm{Y}$ variable." If you want to implement the Granger causality analysis, premise condition that requires time series must have stability. Therefore, it is necessary to carry out ADF test on each indicator before analysis.

ADF test means to check whether there is a unit root in the sequence, and if there is a unit root, then it is a non-stationary time series. If the mean and variance of time series do not change with time, the covariance between two time series values is only correlated with their time intervals. Independent of the specific time point at which the variable is detected, the time series is considered stable. With the passage of time, time series do not have significant change trend. In the regression of time series, if there is no ADF test, it is likely to conclude that there is a very high correlation between time series observed variables, which may lead to the phenomenon of "pseudo-regression".

\subsection{Data Sources}

\subsubsection{Sample Data Selection}

First of all, I first searched and counted the changes in the market since China started margin trading business in 2010 from the website of Shanghai and Shenzhen stock exchanges. As can be seen from the bar chart (Figure 1), the proportion of margin trading in the stock trading market in China has been on the rise, and the margin trading market has been constantly expanding. In particular, it can be seen that the amount of margin trading from 2015 to 2011 is about 91 times, 80 times, 27 times, 7 times and 3 times that of 2010. And from the Shanghai Shenzhen stock exchange data statistics. Up to June 30, 2015, the balance of margin financing and short selling was 2049386 billion yuan (among which, the balance of Shanghai stock exchange was 13384.66 yuan; The Shenzhen certificate balance is 710.92 billion yuan). As can be seen from the data at the end of the year, the margin balance at the end of December was 11,742.68 billion yuan (among which, the balance of Shanghai stock exchange was 6826.33; The Shenzhen certificate balance was 4916.35), which was significantly reduced by half compared to the data in the middle period. To see since 2010, the average level of Chinese securities lending and borrowing business is constantly improve, but can clearly see that in 2015, there have been some reasons caused the obvious fluctuation in the securities lending and borrowing business, so I chose in May 2014 to March 2016, this paragraph of time the stock market data and margin of the data, which contains a total of 469 days. During this period, the policies related to margin lending and short selling did not change significantly. The more active the market, the more favorable it is to study the relationship between the two. 


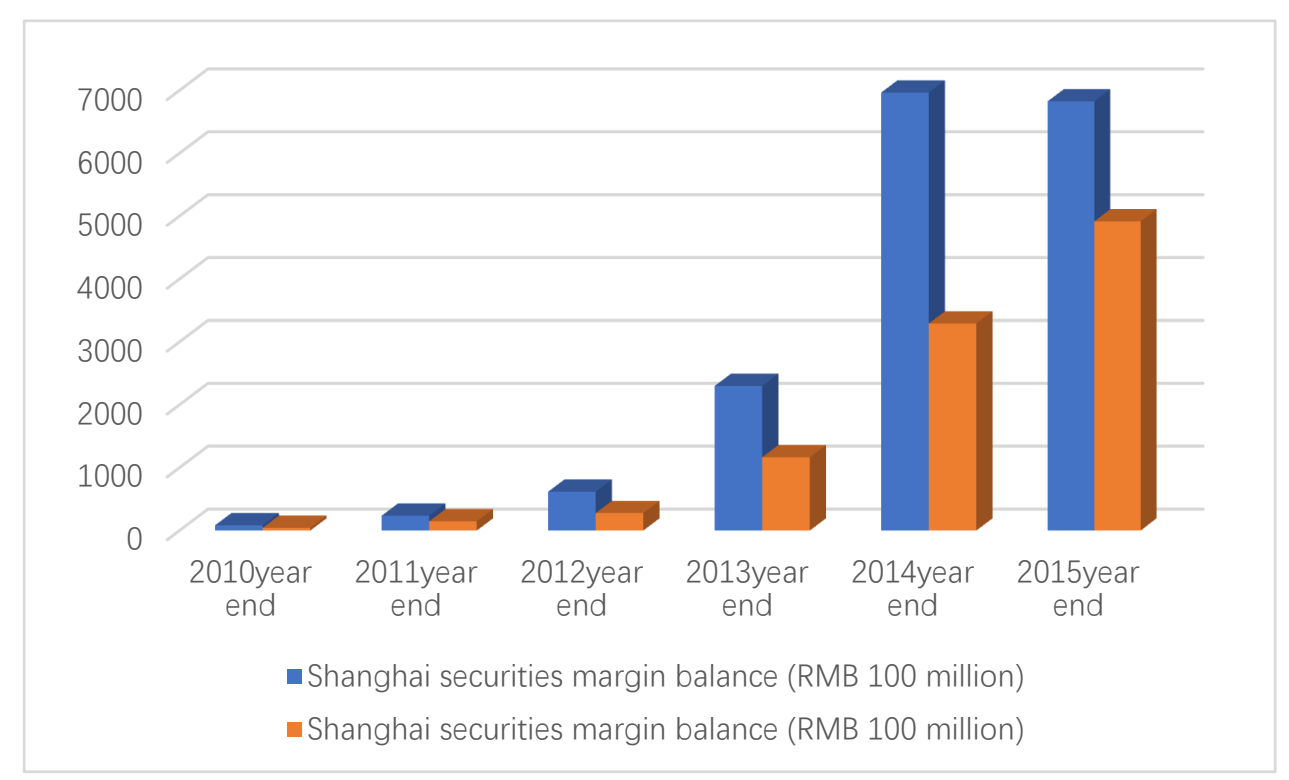

Figure 1. Margin balance data from 2010 to 2015

CSI 300 Index can represent the price level of the a-share market. Set for the sampling size and liquidity of basic standards, awarded the proportion of liquidity is very big, market coverage is high, the samples collected in Shanghai and shenzhen stock market, a large number of quality guarantee stability, the representative of the index, and maneuverability, and when the target is in setting up the index, to the general situation of the stock price in our country securities market change and status display.

In this paper, the three variables selected are balance, daily trading volume and volatility of Chinese stock market. Stock market volatility is expressed in the daily float of stock prices. The macroeconomic data comes from the great wisdom stock trading software and the website of China's national bureau of statistics. Share price information obtained from the official website of yahoo finance and finance, the balance of two stock exchanges in Shanghai and shenzhen from the website.

\subsubsection{Variable Selection}

When analyzing these data, it is found that these series have strong timeliness. Therefore, before the analysis, I need to take the logarithm of the MT and CJL data obtained and calculate the difference, so that I can obtain the data with stationarity.

Table1 study variable definitions

\begin{tabular}{|c|c|c|c|}
\hline $\begin{array}{l}\text { variable } \\
\text { name }\end{array}$ & Variable nature & Economic meaning & Variable definitions \\
\hline Range & $\begin{array}{l}\text { The dependent } \\
\text { variable }\end{array}$ & $\begin{array}{l}\text { The CSI } 300 \text { Index refers to the } \\
\text { volatility reflected by daily } \\
\text { fluctuations }\end{array}$ & $\begin{array}{l}\text { The } \log \text { (high) - } \log \text { (low), in which high and low says the daily } \\
\text { stock balance of high and low margin business }\end{array}$ \\
\hline MT & $\begin{array}{l}\text { The independent } \\
\text { variables }\end{array}$ & $\begin{array}{l}\text { Margin financing and short } \\
\text { selling business balance of } \\
\text { Shanghai and shenzhen stock } \\
\text { markets }\end{array}$ & Margin trading business balance \\
\hline CJL & $\begin{array}{l}\text { The independent } \\
\text { variables }\end{array}$ & $\begin{array}{l}\text { Daily turnover on the CSI } 300 \\
\text { index }\end{array}$ & Daily turnover on the CSI 300 index \\
\hline
\end{tabular}

\subsubsection{Research Hypothesis}

This paper mainly studies the relationship between margin balance and stock market volatility. In this paper, the correlation between margin balance and stock market fluctuation is determined by Granger causality test.

H1: margin balance increase and decrease are positively correlated with stock market volatility 
$\mathrm{H} 2$ : margin balance increase and decrease are negatively correlated with stock market volatility

In a written sense, the margin business may play a stabilizing role in the volatility of the stock market, which is called "market stabilizer". It can increase the supply elasticity of the stock market, ease the situation of sharp fluctuations of the stock market, and implement the function of stability. Just as in order to improve the environment of the stock market, better price stability, ease the pressure of the capital market began to carry out margin lending business.

\section{Empirical Results and Analysis}

\subsection{Stationarity Test}

Before the study of time series, we should first verify the stationarity of the sequences through the $\mathrm{ADF}$ (Augmented Dickey Fuller) test. The regression equation of ADF test is:

$$
\Delta y_{\mathrm{t}}=r y_{t-1}+a+c t+\sum_{i i=1}^{p} \Delta y_{t-i}+e_{t}
$$

(1) The t-statistic value is -20.11281 , which corresponds to a $p$ value close to 0 , indicating a stable Range of sequences.

Table 2. Verify that DRange (stock volatility) sequence is stable

\begin{tabular}{llll}
\hline & & t-Statistic & Prob. \\
\hline Augmented Dickey-Fuller test statistic & & -20.11281 & 0.0000 \\
Test critical values & $1 \%$ level & -3.444189 & \\
& $5 \%$ level & -2.867536 & \\
& $10 \%$ level & -2.570027 & \\
\hline
\end{tabular}

(2) the t-statistic value of -9.894003 , corresponding to $p$ value close to 0 , indicates that the sequence DLNMT is stable.

Table 3. Verify the stable sequence of DLNMT (margin balance)

\begin{tabular}{llcc}
\hline \multicolumn{2}{l}{} & t-Statistic & Prob. \\
\hline Augmented Dickey-Fuller test statistic & & -9.894003 & 0.0000 \\
Test critical values & $1 \%$ level & -3.444128 & \\
& $5 \%$ level & -2.867536 & \\
& $10 \%$ level & -2.570027 & \\
\hline
\end{tabular}

(3) The value of $\mathrm{T}$ statistic is -16.60524 , which corresponds to a $\mathrm{p}$ value close to 0 , indicating that the sequence DCJL is stable.

Table 4. Verify the stationarity of DCJL (volume) sequences

\begin{tabular}{lccc}
\hline & & t-Statistic & Prob. \\
\hline Augmented Dickey-Fuller test statistic & -16.60524 & 0.0000 \\
Test critical values & $1 \%$ level & -3.444189 & \\
& $5 \%$ level & -2.867536 & \\
& $10 \%$ level & -2.570027 & \\
\hline
\end{tabular}

The test results show that after the first-order difference processing of DRange, DLNMT and DCJL, the original hypothesis with unit root is rejected at the significance level of $1 \%$, indicating that there is no unit root in the first-order difference of these three-time series, and the time series of each variable is stable.

\subsection{Cointegration Analysis}

\subsubsection{Establish the Regression Model}

ADF test was performed on DRange, DLNMT and DCJL, and it was found that they were all stable. Therefore, we conducted co-integration test on DRange, DLNMT and DCJL according to the nature of co-integration 
sequence, so as to observe the long-term stable relationship between variables and adopt Johansen co-integration analysis.

Table 5. Results of co-integration test

\begin{tabular}{lllll}
\hline Hypothesized No.of CE(s) & Eigenvalue & Trace Statistic & 0.05 Critical Value & Prob.** \\
\hline None* & 0.285463 & 310.5223 & 29.79707 & 0.0001 \\
At most $1^{*}$ & 0.235908 & 154.8988 & 15.49471 & 0.0001 \\
At most $2^{*}$ & 0.063389 & 30.32043 & 3.841466 & 0.0000 \\
\hline
\end{tabular}

Note. Trace test indicates 3 cointegrating eqn(s) at the 0.05 level;

* denotes rejection of the hypothesis at the 0.05 level;

**MacKinnon-Ha ug-Michelis(1999) p-values.

According to the test results, we can conclude that there are at least three co-integration equations between DRange, DLNMT and DCJL, and the regression model between them is as follows:

$$
\begin{aligned}
D R \text { ange }= & -0.028985 D L N M T+(-3.82 E-11) D C J L \\
& (0.02095) \quad(1.4 \mathrm{E}-11)
\end{aligned}
$$

According to the co-integration equation, the t-statistic values of the variable coefficients of DLNMT and DCJL are all less than the critical value, indicating that the co-integration equation is significant, and it can be preliminarily judged that there is a co-integration relationship between DRange, DLNMT and DCJL, which is stable and mutual in the long run.

\subsubsection{Residual Stability Test}

Using Eviews, the residual term $\mathrm{E}$ is obtained. Then the stability test was conducted, and the results were shown as follows:

\begin{tabular}{|c|c|c|c|}
\hline & & $\mathrm{t}$-Statistic & Prob. \\
\hline \multicolumn{2}{|c|}{ Augmented Dickey-Fuller test statistic } & -20.37020 & 0.0000 \\
\hline \multirow[t]{3}{*}{ Test critical values: } & $1 \%$ level & -3.444189 & \\
\hline & $5 \%$ level & -2.867536 & \\
\hline & $10 \%$ level & -2.570027 & \\
\hline
\end{tabular}

Table 6. Verify that E (residual term) sequence is stable

$$
\begin{gathered}
\Delta \widehat{e}_{t}=-2.162035 \widehat{e}_{t-1} \\
(0.106137)
\end{gathered}
$$

$$
\begin{array}{cc}
R^{2}=0.714878 & \text { DW }=2.015748 \\
\text { LM }(1)=0.65 & \text { LM }(2)=0.23 \\
t=-20.37020<-2.867536 & =A D F_{0.05}
\end{array}
$$

The results show that there is a first-order co-integration relationship between DRange, DLNMT and DCJL. As can be seen from their co-integration equation, the coefficient of variables of DLNMT and DCJL are both negative. Therefore, DRange changes are negatively correlated with DLNMT and DCJL changes. This can indicate that the change of margin trading volume and the volatility of the stock market have the influence of the opposite direction, and to a certain extent, it has the effect of inhibiting the volatility.

\subsection{Granger Causality Test}

It can be seen from the co-integration test that there are at least three co-integration equations with long-term effects between the three variables. In other words, the three variables may have other correlative aspects that affect each other. Therefore, I performed Granger causality test on three variables. Because the choice of lag time 
has a great correlation in the final result of Granger causality test. Therefore, in order to ensure the representativeness and stability of the experimental results, I selected 1 to 3 late stagnancy for testing. The test results are shown in table 7 and a comprehensive and relatively strong conclusion is obtained. The test results are as follows:

Table 7. Granger causality test

\begin{tabular}{|c|c|c|c|}
\hline The null hypothesis & lag time & $P$ value & lag time \\
\hline \multirow{3}{*}{ Range is not the reason for DLNMT ${ }^{\prime} \mathrm{s}$ Granger } & 1 & $3.00 \mathrm{E}-05$ & \multirow{3}{*}{ Reject the null hypothesis } \\
\hline & 2 & 0.0003 & \\
\hline & 3 & $6.00 \mathrm{E}-05$ & \\
\hline \multirow{3}{*}{ DLNMT is not the reason for Range' $s$ Granger } & 1 & 4.00E-06 & \multirow{3}{*}{ Reject the null hypothesis } \\
\hline & 2 & 0.0004 & \\
\hline & 3 & 0.0014 & \\
\hline \multirow{3}{*}{ Range is not the reason for DCJL' s Granger } & 1 & 0.0011 & \multirow{3}{*}{ Unable to determine } \\
\hline & 2 & 0.1751 & \\
\hline & 3 & 0.2040 & \\
\hline \multirow{3}{*}{ DCJL is not the reason for Range ${ }^{\prime} \mathrm{s}$ Granger } & 1 & 0.0223 & \multirow{3}{*}{ Reject the null hypothesis } \\
\hline & 2 & 0.0426 & \\
\hline & 3 & 0.0389 & \\
\hline \multirow{3}{*}{ DCJL is not the reason for DLNMT ${ }^{\prime} \mathrm{s}$ Granger } & 1 & 0.4518 & \multirow{3}{*}{ Accept the null hypothesis } \\
\hline & 2 & 0.5665 & \\
\hline & 3 & 0.2603 & \\
\hline \multirow{3}{*}{ DLNMT is not the reason for DCJL' s Granger } & 1 & 0.0790 & \multirow{3}{*}{ Unable to determine } \\
\hline & 2 & 0.2652 & \\
\hline & 3 & 0.2868 & \\
\hline
\end{tabular}

\subsection{Error Correction Model}

Using the newly obtained stable time series as the error correction term, the error correction analysis can be conducted, as shown in the following table:

Table 8. Error correction analysis

\begin{tabular}{lllll}
\hline Variable & Coefficient & Std. Error & t-Statistic & Prob. \\
\hline C & 0.025226 & 0.000742 & 34.00788 & 0.0000 \\
DLNMT & -0.506988 & 0.052314 & -9.691278 & 0.0000 \\
DCJL & $4.76 \mathrm{E}-11$ & $1.43 \mathrm{E}-11$ & 3.340645 & 0.0009 \\
E(-1) & 0.170531 & 0.055116 & 3.094053 & 0.0021 \\
R-squared & 0.202410 & Mean dependent var & 0.024377 \\
Adjusted R-squared & 0.197242 & S.D. dependent var & 0.017763 \\
S.E. of regression & 0.015915 & Akaike info criterion & -5.434609 \\
Sum squared resid & 0.117269 & Schwarz criterion & -5.399095 \\
Log likelihood & 1272.981 & Hannan-Quinn criter. & -5.420633 \\
F-statistic & 39.16622 & Durbin-Watson stat & 0.965491 \\
Prob(F-statistic) & 0.000000 & & \\
\hline
\end{tabular}

The model can be obtained as follows:

$$
\begin{array}{ccc}
D R \text { ange }=0.025226 & -0.506988 & D L N M T \\
(0.000742)(4.76 E-11) & D C J L+0.170531 & E(-1) \\
(0.052314) & (1.43 \mathrm{E}-11) & (0.055116) \\
R^{2}=0.202410 & \mathrm{DW}=0.965491 &
\end{array}
$$

\section{Research Conclusions and Recommendations}

\subsection{Research Conclusions}

Through empirical analysis, it can be preliminarily concluded that the conclusion is basically in line with the hypothesis $\mathrm{H} 2$ : the increase or decrease of margin balance is negatively correlated with stock market volatility. 
After the Granger causality test, we concluded that DLNMT was one of the factors that caused Range fluctuation, which indicates that the change of margin balance is the factor that leads to the fluctuation of Shanghai and Shenzhen 300 index stocks. But it only shows that during this period of time I choose, the margin trading would be to supply new liquidity. During the time between May 2014 to June 2015, this phase margin trading could be driving one of the causes of the bull market, and because of that, in 2015, our country stock market there may be some speculative bubble, fluctuations in stock prices are likely to be inflated by the growing margin business of commercial Banks. So, It is not difficult to explain the unexpected turn of China's stock market in July and August 2015. Through the analysis of granger causality test results, we can see that the model fitting degree is not high, and the effect of the margin balance of independent variables on the volatility of Shanghai and Shenzhen 300 index is not great. According to the coefficient of the model obtained, when the margin balance increases (or decreases) by $1 \%$, the volatility of Shanghai and Shenzhen 300 index decreases (or increases) by 0.5 points. And after the further analysis of the data, the margin balance is the progressive amount of the business completed every day.

According to the modified equation, the correlation coefficient between the margin balance and the volatility of the CSI 300 index is negative. It can be concluded that margin and short selling business is negatively correlated with the fluctuation of the CSI 300 index. It is explained that the increase (or decrease) of margin balance to some extent will lead to the decrease (or increase) of volatility of stock market of the CSI 300 index. In other words, during the period I chose, margin financing and short selling business played a role of stabilizing the market in actual conditions, and lowered the fluctuation of the stock market at a certain level.

In conclusion, on the day of the 469 open deals between May 2014 to March 2016, I conducted a flatness test of the original data of the obtained variables after calculation of the logarithm or difference. The model was fitted by Eviews measurement software and the regression analysis was performed after Granger causality test, although the fitting degree was not very high, it can be understood that there are many complex factors influencing the volatility of the stock market.

It can be preliminarily concluded that there is a significant correlation between the margin balance and the volatility of Shanghai and Shenzhen 300 index. In this period, the negative correlation is presented, which is to say the margin business during this period played a more stable role in the market. Also In the second half of 2015 , when the stock market was highly volatile, it also played a role to some extent.

\subsection{Research Suggestions}

Based on the conclusions of the study, the following Suggestions are proposed:

Margin trading has the basic functions of making the market stable, discovering price and improving liquidity. For China's securities market, it is necessary to further rules and regulations to play an effective role under theoretical conditions. Prevent abnormal and irrational stock market fluctuations and gradually increase market liquidity in a reasonable and orderly way.

Appropriately lower the threshold for margin trading. At present, according to China's regulations, the amount of funds needed to be more than 500,000 yuan and the opening of an account of six months or more before investors can be qualified for margin trading. In the future, the standard of investors can be lowered to some extent, making it easier for ordinary investors to conduct margin trading and expand the margin trading market, which is conducive to the long-term development of margin trading.

Reduce the cost of margin trading reasonably. The essence of margin trading is lending. At present, the interest rate of financing transaction in China is about $8.6 \%$. and the lending rate is about 10.6 percent. In addition to interest charges, there are high commissions and fees that are far higher than normal transactions. In such cases, consideration needs to be given to the trading experience of overseas mature margin trading related rates, which make the trading activity increases.

Investment risk education can be applied to investors, investor understand that rules of financing coupon, and understand the risks that can be generate, and to some extent objectively assess the ability of the risk tolerance, scientifically choose the investment strategy, reasonably arrange the investment structure, make decision in the investment, which can play some role in the development of the healthy and steady healthy development of the securities market.

\section{References}

Boehmer, E., Jones, C. M., \& Zhang, X. (2013). Shackling short sellers: The 2008 shorting ban. Review of Financial Studies, 26(6), 1363-1400. https://doi.org/10.1093/rfs/hht017 
Cai, X. (2010). Research on the influence of margin trading on stock market. Suzhou University.

Chang, E. C., Luo, Y., Ren, J. J. (2006). Short-selling, margin-trading, and price efficiency: Evidence from the Chinese market. Nature, 439, 457-461.

Chen, M. X., \& Zheng, Z. L. (2008). The effect of margin adjustment on the volatility of securities market: evidence from Taiwan. Research on Financial Problems, (3), 55-60.

Chen, M. X., \& Zheng, Z. L. (2008). The impact of short selling mechanism on stock market volatility. Securities Market Herald, (2), 61-65.

Dong, C. Y., Zhao, P., Liu, W. Q. (2014). Research on the role of margin trading in improving the quality of stock market. Management modernization, 34(6), 13-16.

Gong, H. X. (2010). The impact of margin trading on stock price volatility. Guangdong Institute of Business.

Liang, X. Y., \& Liu, W. M. (2015). Margin trading and stock market fluctuation in China. Friends of accounting, (18), 22-24.

Liao, S. G., \& Yang, C. J. (2005). The influence of short selling mechanism on stock price. Securities Market Herald.

Nie, Z. W. (2015). The impact of margin trading on the volatility of China's stock market. East China University of political science and law.

Peng, Z. H. (2015). The impact of margin trading on stock market volatility. Time Finance, (1), 156-167.

Song, G. X. (2015). The driver of the Great Stock Market of 2015 in China: Evidence and Policy Implications.

Wang, M., Liao, S. G., \& Wu, S. K. (2008). A study on the market shock effect of margin trading -- Based on the experience and Enlightenment of Taiwan stock market. Financial Research, 34(10), 99-109.

Wang, T. D., Sun, Q. (2014). Margin trading and the volatility of financial market -- An Empirical Test Based on China's a shares. Management modernization, (3), 4-6.

Xiao, W. Y., Wang, Z. H. (2012). The impact of margin trading mechanism on the volatility of China's stock market -- An Empirical Analysis Based on Shanghai Stock Exchange 50. China Securities and Futures, (5), 33-35.

Yang, D. Y., \& Wu, Q. (2011). An empirical analysis of the impact of margin trading on Shanghai Stock Market -Based on the perspective of liquidity and volatility. Journal of Central University of Finance and Economics, (5), 28-34.

Yang, Y., Zhang, T. W. (2012). The empirical analysis of margin trading on the volatility of China's stock market -- Based on VAR model. Zhejiang Finance, (8), 59-60.

Yu, X. J. (2012). The impact of margin trading on liquidity and volatility of China's stock market: a case study of Shanghai Stock Market. Journal of South China University of Technology: Social Science Edition,14(2), $1-7$.

\section{Copyrights}

Copyright for this article is retained by the author(s), with first publication rights granted to the journal.

This is an open-access article distributed under the terms and conditions of the Creative Commons Attribution license (http://creativecommons.org/licenses/by/4.0/). 